\title{
LA-UR- $98-2614$
}

Approved for public release, distribution is unilimited.

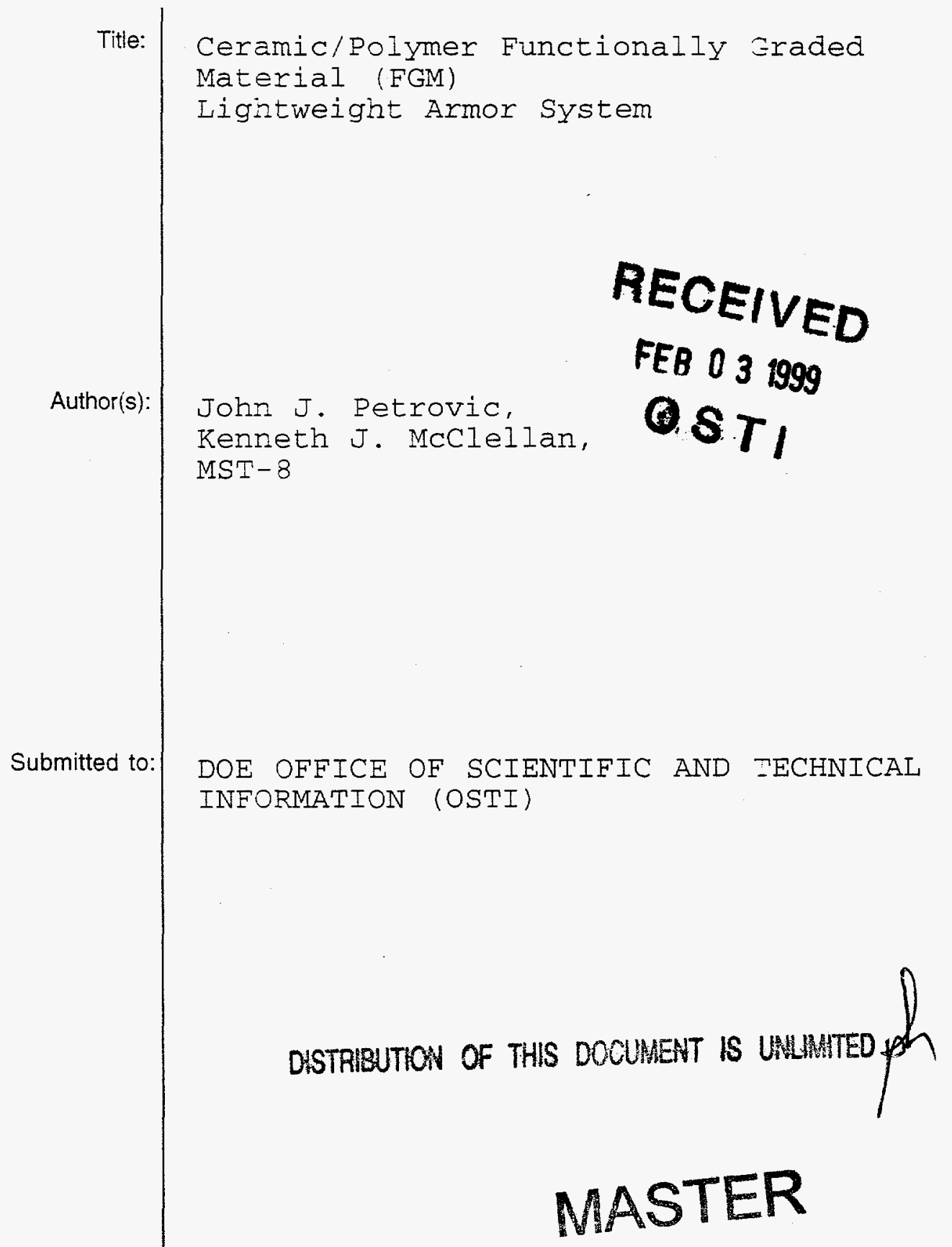

\section{Los Alamos}

\section{NATIONALLABORATORY}

Los Alamos National Laboratory, an affirmative action/equal opportunity employer, is operated by the University of Cailfornia for the U.S. Department of Energy under contract W-7405-ENG-36. By acceptance of this article, the publisher recognizes that the U.S. Government retains a nonexciusive, royalty-free license to publish or reproduce the published form of this contribution, or to allow others to do so, for U.S. Government purposes. Los Alamos National Laboratory requests that the publisher identify this article as work performed under the auspices of the U.S. Department of Energy. The Los Alamos National Laboratory strongly supports academic freedom and a researcher's right to publish; as an institution, however, the Laboratory does not endorse the viewpoint of a publication or guarantee its technical correctness. 


\section{DISCLAIMER}

This report was prepared as an account of work sponsored by an agency of the United States Government. Neither the United States Government nor any agency thereof, nor any of their employees, makes any wartanty, express or implied, or assumes any legal liability or responsibility for the accuracy, completeness, or usefulness of any information, apparatus, product, or process disclosed, or represents that its use would not infringe privately owned rights. Reference herein to any specific commercial product, process, or service by trade name, trademark, manufacturer, or otherwise does not necessarily constitute or imply its endorsement, recommendation, or favoring by the United States Government or any agency thereof. The views and opinions of authors expressed herein do not necessarily state or reflect those of the United States Government or any agency thereof. 


\section{DISCLAIMER}

Portions of this document may be illegible in electronic image products. Images are produced from the best available original document. 


\title{
Ceramic/Polymer Functionally Graded Material (FGM) Lightweight Armor System
}

John J. Petrovic* and Kenneth J. McClellan

\begin{abstract}
This is the final report of a two-year. Laboratory Directed Research and Development (LDRD) project at the Los Alamos National Laboratory (LANL). Functionally graded material is an enabling technology for lightweight body armor improvements. Our objective was to demonstrate the ability to produce functionally graded ceramic-polymer and ceramicmetal lightweight armor materials. This objective involved two aspects. The first and key aspect was the development of graded-porosity boron-carbide ceramic microstructures. The second aspect was the development of techniques for liquid infiltration of lightweight metals and polymers into the graded-porosity ceramic. We were successful in synthesizing boron-carbide ceramic microstructures with graded porosity. These graded-porosity boron-carbide hot-pressed pieces were then successfully liquid-infiltrated in vacuum with molten aluminum at $1300^{\circ} \mathrm{C}$, and with liquid polymers at room temperature. Thus, we were able to demonstrate the feasibility of producing boron carbide-aluminum and boron carbide-polymer functionally graded materials.
\end{abstract}

\section{Background and Research Objectives}

Improvements in body armor is one of the Department of Defense (DoD) "Top Ten Tough Problems," falling under the heading of soldier survivability/mobility/lethality. Conventional body armor uses polymeric materials because of their light weight and flexibility, but these materials alone can only provide limited protection to the wearer.

The advent of modern ballistic protection for personnel was based on the development of Kevlar by the Dupont Corporation. Body armor, using multiple layers of Kevlar fabric, was developed by the Army's Edgewood Arsenal and the Natick R\&D Command in the early 1970s and was presented to armor manufacturers in 1974. This material was a vast improvement over the ballistic nylon-based body armors worn in World War II and known as "flak jackets."

\footnotetext{
"Principal Investigator, e-mail: petrovic@ lanl.gov
} 
Since Kevlar was introduced, incremental improvements have been made to the material, and manufacturers have developed a wide variety of products for military and civilian (police) markets. The following table shows National Institute of Justice (NIJ) threat levels. Threat levels up to NIJ standard class III-A (.44 Magnum handgun and $9 \mathrm{~mm}$ submachine gun) can be defeated with "soft" body armor; that is, body armor composed solely of layers of Kevlar fabric. To defeat greater threats, including all common rifles, hard ballistic plates (normally ceramic plates) are attached to the exterior of the vest. Even

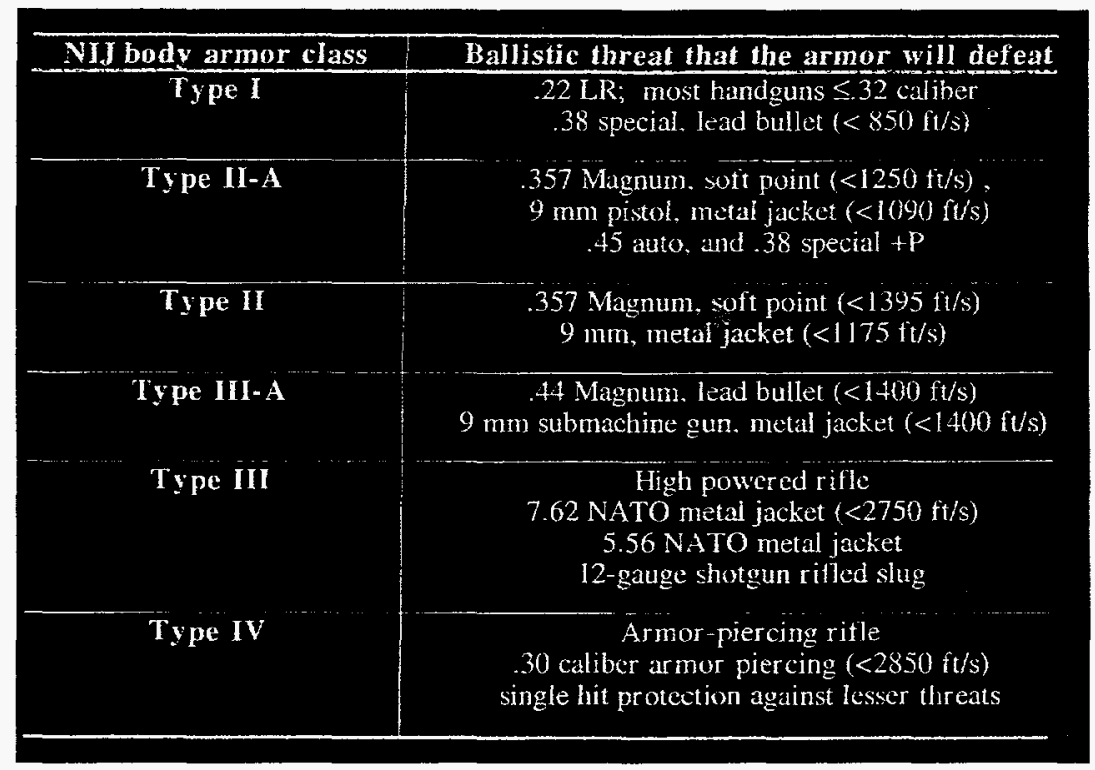

the class III-A vests are so heavy, bulky, and stiff that they are considered to be unsuitable for routine wear. Soldiers trying to protect themselves in urban warfare situations must be prepared for rifle fire using both full-metal-jacket and armor-piercing (designated APM2) rifle bullets at velocities up to $2850 \mathrm{feet} / \mathrm{second}$ (up to NIJ class IV). Current vests are capable of defeating up to a class III threat by incorporating aluminum-oxide ceramic plates over the front and back trunk area. These plates fit into pockets on the chest and back of the vest.

Our research objective was to demonstrate the ability to produce functionally graded materials (FGMs), such as functionally graded ceramic-polymer and ceramic-metal materials, which could form the basis for a quantum-leap improvement in lightweight body armor systems. Such materials would allow the development of lightweight, high-threatcapability, body armor vests with flexible design, heat-load management, multi-hit/multithreat capability, and increased extremity coverage. The FGM material is the enabling technology for such body armor improvements, since it addresses the weight and threat issues. 
Importance to LANL's Science and Technology Base and National R\&D Needs

Los Alamos National Laboratory (LANL) has a core competency in Nuclear and Advanced Materials. FGMs have many potential applications in addition to lightweight armor. The boron carbide-metal and boron carbide-polymer FGM materials that have been developed could also find applications in automotive wear components, where lightweight materials are of importance. In addition, many industrial applications require materials that are resistant to wear, corrosion, and erosion in hostile environments.

In the area of nuclear materials, ceramic-metal and ceramic-polymer FGMs may be useful for the fabrication, handling, and storage of plutonium materials. Molten plutonium is a very reactive substance, and highly stable ceramics in contact with it could be graded to metals for structural support.

\section{Scientific Approach and Accomplishments}

\section{Concept}

Functionally Graded Materials are emerging as a frontier area of materials science. FGMs possess microstructurally engineered gradual transitions in microstructures and/or compositions, and the presence of these gradients is motivated by functional performance requirements that may vary with location in a component. In FGMs, material compositions and material properties transition gradually, rather than abruptly, from one end-phase material to another end-phase material. Hence there is a gradual, rather than distinct, interface between the two end members.

FGMs have distinct opportunities as lightweight body armor materials. FGMbased armor is the evolution from laminate and cermet materials to a material that provides a hard face that gradually transitions to a shock-absorbing backing. This FGM concept is shown in Figure 1. The foundation of this concept is the graded porosity ceramic, which is fully dense on the front face, leading to open porosity on the back face. Polymer or metal is then infiltrated into the porous side of the ceramic plate to provide a lightweight energyabsorbing backing. A ballistic fiber weave, such as Kevlar, could also be embedded in the polymer backing to provide constraint and enhanced ballistic protection.

FGM armor has the following advantages. First, the hard, dense ceramic face will significantly blunt the projectile. Second, the gradual transition to the ductile, tough material will lead to significant energy absorption and shrapnel containment, and should also disperse reflected tensile shock waves from the back face so that they do minimal damage to the hard ceramic face. Finally, a built-in lateral constraint would enhance ballistic performance by keeping fractured ceramic material contained and in place. 


\section{Approach}

We have worked to demonstrate the ability to produce functionally graded ceramicpolymer and ceramic-metal lightweight armor materials. This involves two aspects. The first and key aspect is the development of graded-porosity ceramic microstructures. The second aspect is the development of techniques for liquid infiltration of lightweight metals and polymers into the graded-porosity ceramic.

\section{Materials}

In terms of lightweight armor materials systems, boron carbide $\left(\mathrm{B}_{4} \mathrm{C}\right)$ was selected as the ceramic material. $\mathrm{B}_{4} \mathrm{C}$ is a very lightweight (density $2.52 \mathrm{gm} / \mathrm{cm}^{3}$ ), very hard (hardness $35 \mathrm{GPa}$ ) ceramic [1], and these properties make it the best ceramic choice for lightweight body armor. Aluminum has been chosen as the metal material for infiltration into the $\mathrm{B}_{4} \mathrm{C}$, since it is a very lightweight metal and because there has been previous work performed on the fabrication and armor characteristics of $\mathrm{Al}-\mathrm{B}_{4} \mathrm{C}$ cermets. With regard to the polymer materials, we explored the use of Ciba Geigy 0510 epoxy, due to its excellent wetting behavior with $\mathrm{B}_{4} \mathrm{C}$, and Adiprene L-100 urethane rubber, due to its remarkable stress-wave damping ability.

\section{Graded Porosity in $\mathrm{B}_{4} \mathrm{C}$}

Our approaches to achieving graded-porosity $\mathrm{B}_{4} \mathrm{C}$ microstructures involved both densification-aid gradients and green-density gradients. It is important to note that this graded-porosity $\mathrm{B}_{4} \mathrm{C}$ technology did not exist, and that we were breaking new ground in its development. We wished to develop graded-porosity processing approaches that were both cost effective and commercially viable.

Because of its high melting point and the covalent nature of its atomic bonding, $\mathrm{B}_{4} \mathrm{C}$ requires high sintering and/or hot pressing temperatures for its consolidation. It has been observed that carbon additions to $\mathrm{B}_{4} \mathrm{C}$ make this material easier to densify [2]. Typically, carbon additions of at least $6 \mathrm{wt} . \%$ carbon are required to significantly reduce consolidation temperatures. We employed furfuryl alcohol $\left(\mathrm{C}_{5} \mathrm{H}_{7} \mathrm{O}_{2}\right)$ as the precursor material for carbon additions to $\mathrm{B}_{4} \mathrm{C}$ powders. Since furfuryl alcohol is a liquid at room temperature, it can be employed to uniformly coat $\mathrm{B}_{4} \mathrm{C}$ powder particles, as well as also serve as a binder material. Upon heating to a maximum temperature of $850^{\circ} \mathrm{C}$, the furfuryl alcohol decomposes to a very fine carbon, with a high carbon yield of $40 \mathrm{wt}$.\% carbon.

We also pursued the green density approach to obtaining graded-porosity $\mathrm{B}_{4} \mathrm{C}$. This approach employs different particle-size distributions of $\mathrm{B}_{4} \mathrm{C}$ powders. We worked 
with three different $B_{4} C$ powder grades from ESK. The $F 400$ powder has an average particle size of approximately $30 \mu \mathrm{m}$. The F1200 powder has an average particle size of approximately $5 \mu \mathrm{m}$. The $3000 \mathrm{~F}$ powder has an average particle size of approximately 0.4 $\mu \mathrm{m}$.

\section{Liquid Infiltration of Aluminum into Graded Porosity $\mathrm{B}_{4} \mathrm{C}$}

Previous investigations on $\mathrm{B}_{4} \mathrm{C}-\mathrm{Al}$ cermets have shown that molten aluminum metal can readily be infiltrated into porous $\mathrm{B}_{4} \mathrm{C}[3]$. $\mathrm{B}_{4} \mathrm{C}$ and $\mathrm{Al}$ are reactive materials, and various compounds can form based upon the temperature and time of liquid infiltration. Contact angles of molten $\mathrm{Al}$ on $\mathrm{B}_{4} \mathrm{C}$ are shown in Figure 2. The contact angle is very important for liquid infiltration. The lower the contact angle, the easier it is to obtain infiltration.

\section{Liquid Infiltration of Polymers into Graded Porosity $B_{4} C$}

Ciba Geigy 0510 epoxy is a polymer that has been employed previously at LANL to infiltrate porous $\mathrm{B}_{4} \mathrm{C}$ structures. This epoxy has been observed to wet the $\mathrm{B}_{4} \mathrm{C}$ well, which is a necessary condition of good infiltration of porous structures. For this reason, it was selected for use in the present investigation.

Adiprene L-100 is a urethane rubber that is one of a series of liquid urethane polymers that can be cured to a strong, rubbery solid by reaction of the isocyanate groups with polyamine compounds. This material is commercially available from the Uniroyal Chemical Company, Inc. Adiprene L-100 has a density of $1.06 \mathrm{gm} / \mathrm{cm}^{3}$, a hardness of 90 (durometer A), $100 \%$ modulus of 1100 psi, tensile strength of $4500 \mathrm{psi}$, and elongation to fracture of $450 \%$.

This material is of interest as a polymer infiltrant into graded porosity $\mathrm{B}_{4} \mathrm{C}$ because of recent Hopkinson Bar stress-wave experiments conducted at LANL for the Navy, which helped assess its acoustic damping for submarine applications. Specifically, the transmitted stress waves in Hopkinson Bar tests of this material are severely attenuated so that, in effect, there is no transmitted stress wave through the material. These results indicate that Adiprene L-100 possesses superb stress wave attenuation capabilities, and make it an interesting and potentially important candidate for the polymer in FGM lightweight body armor.

\section{Accomplishments}

We have demonstrated the feasibility of using the furfuryl alcohol carbon source to produce graded porosity in $\mathrm{B}_{4} \mathrm{C}$. In one approach, furfuryl alcohol was painted on one 
surface of a $6.35 \mathrm{~mm}$ thick pressed-powder $\mathrm{B}_{4} \mathrm{C}$ pellet. The furfuryl alcohol penetrated into the powder porosity to a certain depth in the green pellet. The pellet was then hot pressed for high temperature consolidation. A porosity gradient of $25 \%$ porosity on the furfuryl alcohol painted side to $37 \%$ porosity on the unpainted side was observed. This result has demonstrated the feasibility of the furfuryl alcohol approach for grading porosity in $\mathrm{B}_{4} \mathrm{C}$.

By mixing F400 powder and 3000F powder together and then vibrating the mixed powders, we have demonstrated that a porosity gradient can be produced in a $6.35-\mathrm{mm}$ hot-pressed pellet from $53 \%$ porosity at one end of the pellet, to $70 \%$ porosity at the other end. This porosity gradient is due to the fact that, during vibration, the finer $3000 \mathrm{~F}$ powder infiltrates into the interstices of the coarser F400 powder in a graded manner through the thickness of the powder pellet. This effectively produces a gradient in green density from one end of the pellet thickness to the other. which then translates into a gradient in hot-pressed density when the pellet is subsequently hot pressed. This result has demonstrated the feasibility of the mixed-powder size distribution approach to produce graded porosity in $\mathrm{B}_{4} \mathrm{C}$.

We have also employed the differently sized $\mathrm{B}_{4} \mathrm{C}$ powders to produce gradedporosity materials by a layering approach. Here, a layered arrangement of different sized $\mathrm{B}_{4} \mathrm{C}$ powders is placed inside a hot pressing die, and then the layered arrangement is hot pressed, typically at $1900^{\circ} \mathrm{C}$. Figure 3 shows a $\mathrm{B}_{4} \mathrm{C}$ graded porosity material made by this layering approach. Here, the following layers of $\mathrm{B}_{4} \mathrm{C}$ powders were stacked up: $3000 \mathrm{~F}$, mixed 3000F/F1200, F1200, mixed F1200/F400, F400. The porosity ranges in the layers were: $6 \%, 10 \%, 13 \%, 41 \%$, and $53 \%$, respectively. Ultrasonic vibration of the stacked layers prior to hot pressing appears to be effective in grading out the porosity at the layer boundaries, as shown in Figure 3.

Our experiments on the infiltration of molten $\mathrm{Al}$ into graded-porosity $\mathrm{B}_{4} \mathrm{C}$ have shown that vacuum infiltration conditions at a high temperature of $1300{ }^{\circ} \mathrm{C}$ and short times give the best infiltration conditions (due to the low contact angles), as well as minimize reactions between the $\mathrm{Al}$ and $\mathrm{B}_{4} \mathrm{C}$. Using such conditions, $\mathrm{B}_{4} \mathrm{C}$-aluminum FGMs were successfully produced using the graded-porosity $\mathrm{B}_{4} \mathrm{C}$ microstructures.

Vacuum infiltration was also employed to infiltrate polymers into the gradedporosity $\mathrm{B}_{4} \mathrm{C}$. The Ciba Geigy 0510 epoxy was observed to readily infiltrate the $\mathrm{B}_{4} \mathrm{C}$ due to its good wetting characteristics with $\mathrm{B}_{4} \mathrm{C}$. However, the Adiprene L-100 urethane rubber did not readily infiltrate the $\mathrm{B}_{4} \mathrm{C}$, presumably due to poor wetting characteristics. Even so, the feasibility of $\mathrm{B}_{4} \mathrm{C}$-epoxy ceramic-polymer FGMs was clearly demonstrated by the project. 


\section{References}

[1] Thevenot, L. F., "Boron Carbide-A Comprehensive Review," J. European Ceram. Soc. 6, 205-225 (1990).

[2] Dole, S. L. and Prochazka. S., "Densification and Microstructure Development in Boron Carbide," pp. 1151-1160 in Proceedings, January 1985 American Ceramic Society Cocoa Beach Meeting, Cocoa Beach, Florida.

[3] Halverson, D. C., Pyzik. A. J., Aksay, I. A., and Snowden, W. E., "Processing of Boron Carbide-Aluminum Composites," J. Am. Ceram. Soc. 72, 775-780 (1989). 


\section{FGM Ceramic/Polymer Armor Plate}

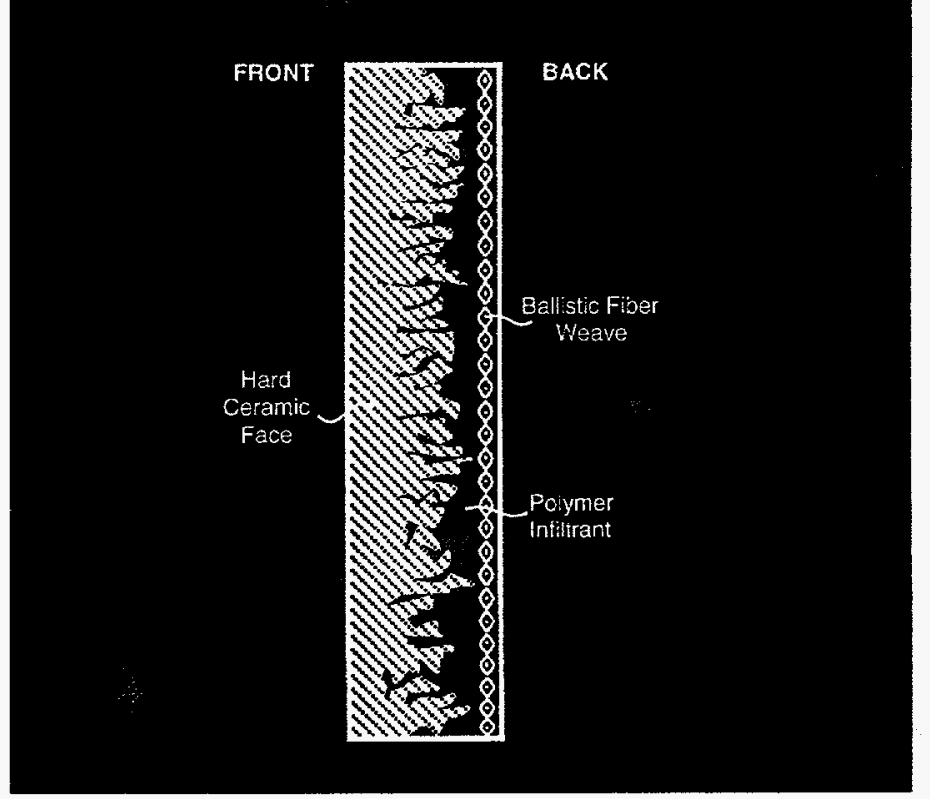

Figure 1. Functionally Graded Material (FGM) lightweight armor concept. 


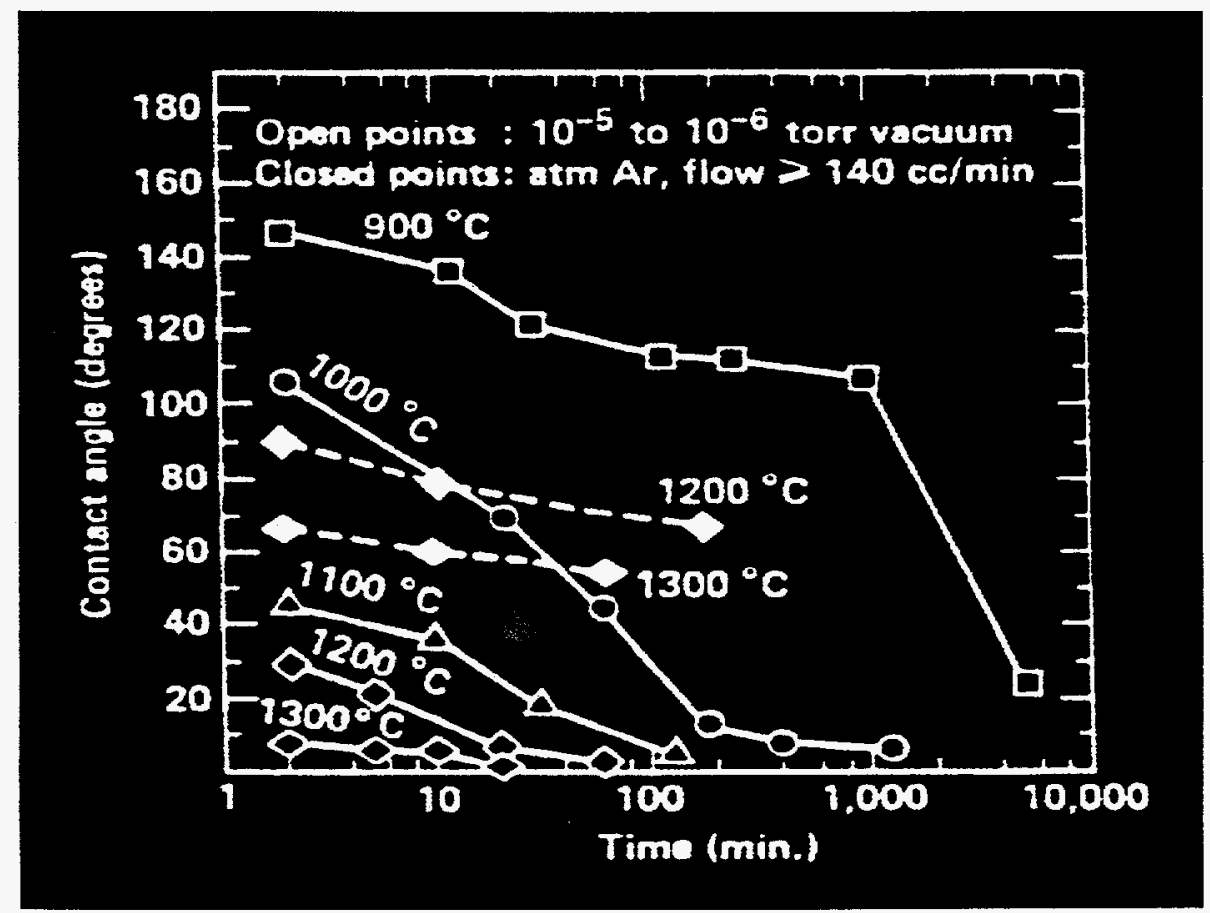

Figure 2. Contact angles between molten $\mathrm{Al}$ and $\mathrm{B}_{4} \mathrm{C}$, as a function of temperature and time [3]. 


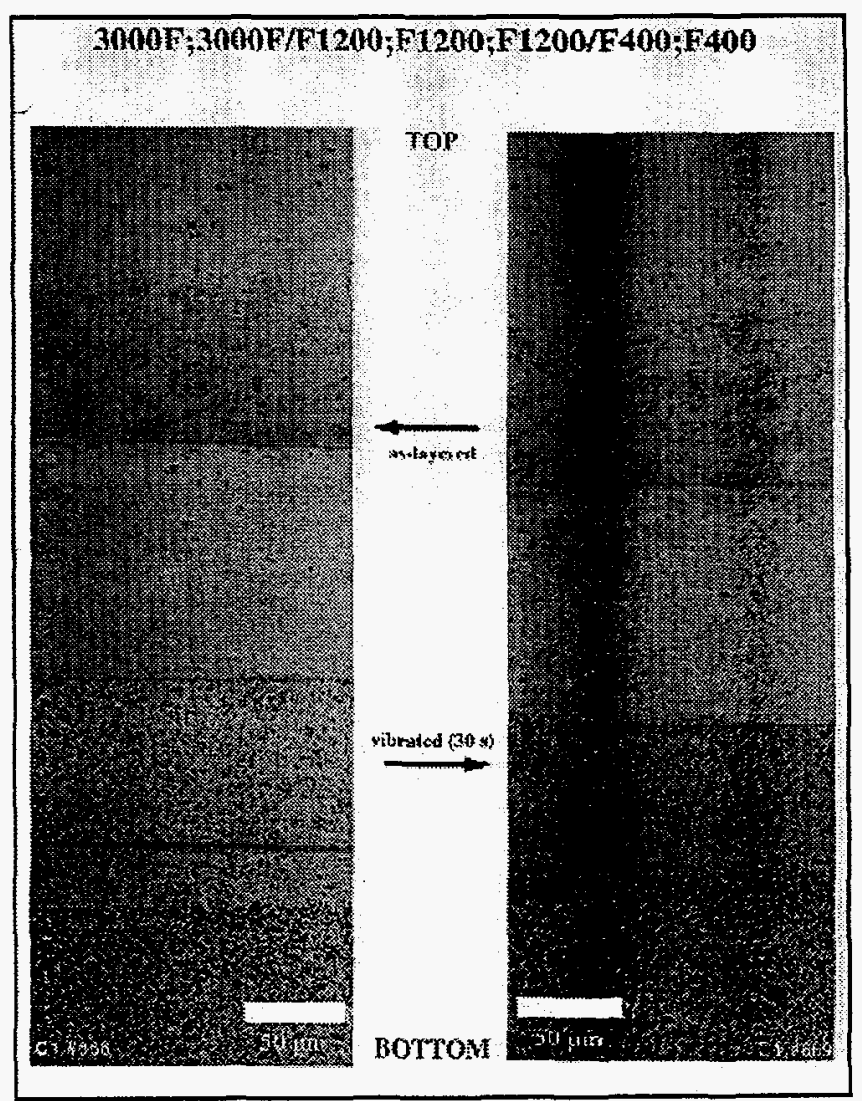

Figure 3. Graded porosity produced in $\mathrm{B}_{4} \mathrm{C}$ by layering of $\mathrm{B}_{4} \mathrm{C}$ powders with different size distributions. 